\title{
Experimental Study on Primary Scale Formation and Descalability on Steels Containing $\mathrm{Ni}$ and $\mathrm{Ni}+\mathrm{Si}$
}

\author{
Wanda MELFO, ${ }^{1) *}$ Henk BOLT, ${ }^{1)}$ Marco RIJNDERS, ${ }^{1)}$ Dirk STAALMAN, ${ }^{11}$ Cristina BENITO CASTRO, ${ }^{2)}$ \\ David CROWTHER ${ }^{1)}$ and Buddhadev JANA ${ }^{2)}$ \\ 1) Tata steel, R\&D, IJmuiden site, 1970CA The Netherlands and Rotherham site, S603AR United Kingdom. \\ 2) Tata steel, TEC, IJmuiden site, 1970CA The Netherlands and Rotherham site, S603AR United Kingdom.
}

(Received on November 14, 2012; accepted on February 6, 2013)

\begin{abstract}
Nickel and silicon are attractive alloying elements for high-strength low-alloyed (HSLA) steel production. However, it is well known that the presence of $\mathrm{Ni}$ and $\mathrm{Si}$ in the steel can impair the surface quality, making it unsuitable for certain markets. The combined effects of $\mathrm{Ni}+\mathrm{Si}$ on the oxide scale formation are still relatively unknown. Literature is dealing mostly with steels containing combinations of $\mathrm{Ni}$ and $\mathrm{Si}$, with either traces of nickel $(0.1 \%)$ or very high (8-16\%) nickel levels. At Tata Steel we explored the effect of an optimum composition selected to achieve steel properties $(0.15 \% \mathrm{Si}$ and $1 \% \mathrm{Ni})$ on the formation of oxide in the reheating furnace and its descalability. Pilot hydraulic descaling trials were performed on blocks of three steel grades, applying reheating and hydraulic descaling in conditions closely resembling the industrial practice.

The oxidation experiments show that synergistic effects occurring during the oxidation of alloys containing $\mathrm{Ni}(1.1 \%)$ are already obvious at relatively low levels of $\mathrm{Si}$ of $0.05 \%$. This effect is even enhanced at higher Si levels of $0.15 \%$ and consists of increasing the adherence of oxide scale to the steel substrate by forming an entangled layer with oxidic pegs.

In order to maximize descalability of (Ni,Si)-alloyed steels slabs, the metal/scale entanglement has to be minimised. In this respect, it was found that the slab surface temperature is the most important parameter. A gentle, smooth reheating process is required in which slab surface temperatures exceeding $1300^{\circ} \mathrm{C}$ should be avoided.
\end{abstract}

KEY WORDS: HSLA; hot rolling; oxides; descaling; Si; Ni.

\section{Introduction}

Nickel and silicon are attractive alloying elements for high-strength low-alloyed (HSLA) steel production. They are readily available and can effectively increase toughness and strength by adding only a fraction of a percent into the steel composition. However, it is well known that the presence of $\mathrm{Ni}$ and $\mathrm{Si}$ in the steel can impair the surface quality because they promote the formation of red or black stripes on the hot rolled product surface. ${ }^{1-3)}$ The presence of these stripes affects the aspect of the hot rolled product, making it unsuitable for certain markets.

The steel produced by continuous casting is cut into slabs that are reheated in natural gas combustion furnaces until average temperatures of $1250^{\circ} \mathrm{C}$ and then discharged to the hot strip mill to be rolled to desired thicknesses. The surface of the steel is exposed to the waste combustion gases of the furnace and then to the humid air of the mill. Therefore, the surface is continuously undergoing oxidation. In order to avoid excessive oxide scale formation and surface defects caused by rolled-in scale particles, this oxide scale is eliminated twice during the process - before both the roughing

* Corresponding author: E-mail: wanda.melfo@tatasteel.com DOI: http://dx.doi.org/10.2355/isijinternational.53.866 passes and the finishing passes- by hydraulic descaling jets. The occurrence of the red and black stripe defect is associated to the poor descaling of the oxides formed in the reheating furnaces. ${ }^{4}$

Since nickel has lower oxygen affinity than iron, it is not oxidised under the conditions of reheating in industrial furnaces. Instead, the $\mathrm{Ni}$ remains in the metallic phase as enrichment near the metal/scale interface, and becomes progressively surrounded by the iron oxides formed during processing in the reheating furnace. Therefore, the scale formed in the furnaces consists of an external layer of iron oxides and an inner interface layer entangled with the steel. It has been found that the inner scale has nickel in metallic form that binds the oxides of the scale with the steel via filaments. ${ }^{5)}$ The whole interface layer cannot be removed by the action of the hydraulic descaler after the furnace and the residuals of scale are rolled-in during further processing.

The mechanism forming oxides scales difficult to descale in steels containing silicon is totally different than in the case of nickel containing steels. At the oxide/steel interface of steels with silicon, iron silicates are formed and the eutectic formed by fayalite $\left(\mathrm{Fe}_{2} \mathrm{SiO}_{4}\right)$ and wüstite $(\mathrm{FeO})$ - or silica $\left(\mathrm{SiO}_{2}\right)$, depending on the amount of silicon- can be at a temperature as low as $1177^{\circ} \mathrm{C} .^{6)}$ At the usual surface tempera- 
tures of a slab during reheating, i.e. between $1230-1300^{\circ} \mathrm{C}$, part of the formed oxides at the interface steel-oxide will be liquid. The liquid oxide phase penetrates surface cracks and grain boundaries, forming an entangled interface that acts as mechanical anchor of the oxide into the steel. ${ }^{4,7)}$ Moreover, the diffusivity of any element is much higher in the liquid phase, thus the oxidation rate of iron is increased and thicker oxides are formed.

The individual effects of either $\mathrm{Ni}$ or $\mathrm{Si}$ as alloying element in steels is quite well known, but the combined effects of $\mathrm{Ni}+\mathrm{Si}$ on the oxide scale formation is still relatively unknown. Literature is dealing mostly with steels containing combinations of $\mathrm{Ni}$ and $\mathrm{Si}$, with either traces of nickel $(0.1 \%)$ or very high $(8-16 \%)$ nickel levels. Asai et al. ${ }^{3)}$ studied experimentally the descalability of a range of steel compositions with $\max 0.1 \% \mathrm{Si}$ and $\max 0.11 \% \mathrm{Ni}$ in low carbon steels. They measured the thickness of the remaining scale after descaling of steels with traces of silicon $(0.02 \% \mathrm{Si})$ and found that the amount of the residual scale after reheating increased considerably when adding only $0.05 \%$ or $0.1 \% \mathrm{Ni}$. For these very low silicon steels, the results after reheating at $1100^{\circ} \mathrm{C}$ and $1200^{\circ} \mathrm{C}$ were very similar. However, when $0.1 \% \mathrm{Si}$ was added, the reheating temperature started to play a significant role in adhesion of the scale. When reheated at $1250^{\circ} \mathrm{C}$, large amounts of remnant scale were found on the surface of steels containing $0.11 \% \mathrm{Ni}$ and $0.1 \% \mathrm{Si}$ even after applying maximum descaling power. After reheating of the same steel at $1150^{\circ} \mathrm{C}$, the scale remnants were considerably lower and dependent on the impact of descaling. It is obvious that also reheating conditions and not only the steel composition must be considered when studying descalability of steels containing both $\mathrm{Ni}$ and $\mathrm{Si}$.

Marston et al. ${ }^{1)}$ have reported a unique study on oxide scale formation on various steel, including $\mathrm{Ni}-\mathrm{Si}$ alloyed steels, with compositions close to HSLA containing 0.5 to $1.9 \% \mathrm{Ni}$ and $0.2 \% \mathrm{Si}$. The furnace conditions included a soaking time of $100 \mathrm{~min}$ at $1250^{\circ} \mathrm{C}$. They found that the steel with relatively low nickel content $(0.5 \% \mathrm{Ni})$ could be only descaled partially as a layer of scale remained on the surface. That scale remnant was formed by an entangled layer with oxidic pegs. The scale on the steel with higher nickel content of $1.9 \%$ could not be descaled at all, and patches containing the whole oxide scale formed in the furnace could be found on the surface. Unfortunately, an in-depth analysis of the interface or the mechanism of the interface formation was not the scope of that report. No description of the interface formation mechanism on steels with medium $(0.1-1.0 \%)$ nickel contents and low Si contents $(0.05-$ $0.2 \%$ ) and the effect of reheating conditions in descalability have been reported.

At Tata Steel we explored the potential of developing Ni$\mathrm{Si}$ alloyed steels with mechanical properties targeting a certain market. Being aware of the issues regarding strip surface quality that could arise, we explored the effect of the optimum composition selected to achieve steel properties $(0.15 \% \mathrm{Si}$ and $1 \% \mathrm{Ni}$ ) on the formation of oxide in the reheating furnace and its descalability. The conditions of experimentation were restricted to the current windows for processing these types of steels and the current descaling capabilities of the descaler located before the roughing mill in the hot strip mill at Tata steel's IJmuiden site. In this view, pilot hydraulic des- caling trials were performed on blocks of three steel grades, applying reheating and hydraulic descaling in conditions closely resembling the industrial practice.

\section{Method}

Three types of steel compositions were cast for the experiments. Firstly, an alloy without nickel and a $0.15 \% \mathrm{Si}$ addition; secondly an alloy with $1.1 \% \mathrm{Ni}$ and just a trace $(0.05 \%)$ of $\mathrm{Si}$; and third an alloy containing $0.15 \% \mathrm{Si}$ in combination with $1.1 \% \mathrm{Ni}$ (as shown in Table 1) were cast. Samples from the cast ingots were cut in blocks of $70 \times 70 \times 100 \mathrm{~mm}$. All the initial surfaces were polished with 800 grit grinding paper, in order to prepare test blocks with oxide-free initial surfaces.

Reheating was done in a muffle furnace, with an atmosphere of combustion products produced by a flame of natural gas. The ratio air/fuel was tuned to obtain an atmosphere as close as possible to the industrial reheating furnaces combustion waste products:

$$
8.8 \% \mathrm{CO}_{2} ; 1.7 \% \mathrm{O}_{2} ; 18 \% \mathrm{H}_{2} \mathrm{O}_{\text {vapour }} ; \text { rest } \mathrm{N}_{2}
$$

The temperature cycles were selected according to slab temperature calculations made with Tata steel's in-house industrial furnace models. The condition necessary to ensure the required mechanical properties was a minimum temperature of $1230^{\circ} \mathrm{C}$ for at least 5 minutes in the coldest part of the slab. This requirement can be achieved by various combinations of reheating furnace process parameters. In the model calculations, the varied parameters were slab transport speed in the furnace, heating power and slab charging temperature. Four possible regimes of reheating were selected by this method, two of them simulate the hot charging procedure $\left(400^{\circ} \mathrm{C}\right.$ slab entry temperature in the furnace) and the other two simulate feeding the furnace with a totally cold slab. Only the surface temperatures of slabs in the furnace were taken into account for the pilot mill experiments. The calculated surface temperatures were subsequently simplified for the purpose of designing temperature-time profiles, consisting of linear segments, for laboratory-scale reheating and descaling trials.

In Fig. 1, the surface temperature-time cycles used in the experiments are shown. Each square in the curves represent one sample; so in test 4, one sample was extracted after the whole cycle; while in test 1 , three samples were extracted (after $100 \mathrm{~min}, 125 \mathrm{~min}$ and $145 \mathrm{~min}$ in the furnace). In all tests, the samples were quickly heated to $1000^{\circ} \mathrm{C}$, since it was considered that metal/scale entanglement does not occur yet below $1000^{\circ} \mathrm{C}$ and scale growth is still very limited, compared to the total scale growth at the end of the test. Test 1 and 2 represent a slab charged from room temperature, while test 3 and 4 are exemplifying hot charging meth-

Table 1. Composition of the steels prepared for the experiments.

\begin{tabular}{lclcc}
\hline & \multicolumn{4}{c}{ Content $\mathrm{wt} \%$} \\
\cline { 2 - 5 } & $\mathrm{C}$ & $\mathrm{Ni}$ & $\mathrm{Si}$ & $\mathrm{Mn}$ \\
\hline Alloy A & 0.06 & 0 & 0.15 & 1.8 \\
Alloy B & 0.06 & 1.1 & 0.05 & 1.6 \\
Alloy C & 0.06 & 1.1 & 0.15 & 1.6 \\
\hline
\end{tabular}




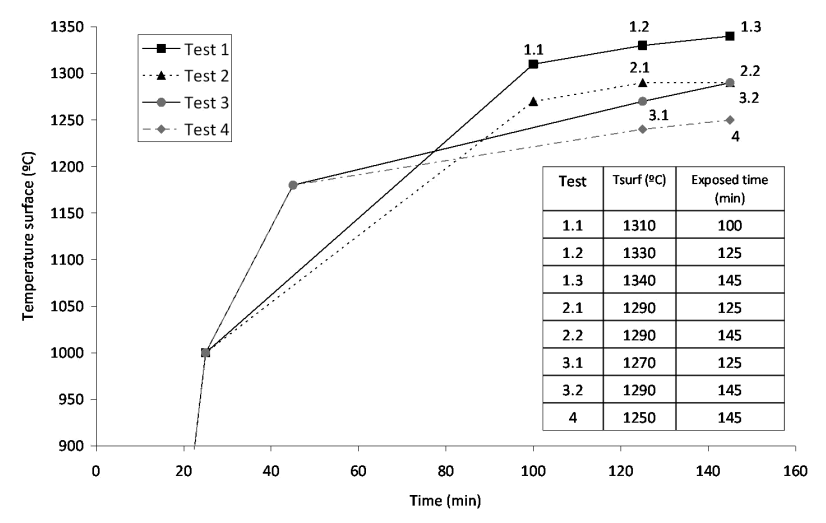

Fig. 1. Regimes of reheating temperatures selected for the experiments. They represent the surface temperature on a slab, which will be the surface temperature of the test blocks. Each square in the curve is a sample.

od, with slabs entering at $400^{\circ} \mathrm{C}$ into the furnace. Therefore, test 3 and 4 are characterised by relatively fast heating rates below $1180^{\circ} \mathrm{C}$, followed by slow further heating to a final surface temperature of $1250^{\circ} \mathrm{C}$ (test 4) or $1290^{\circ} \mathrm{C}$ (test 3). In tests 1 and 2 , it is simulated that a cold slab charging requires more aggressive heating to higher surface temperatures to maintain a similar furnace output rate whilst ensuring that the coldest spot in the slab has reached the minimum required temperature.

After reheating, samples were immediately descaled in a descaling rig. The descaling system of Tata Steel R\&D comprises:

a) furnace with controlled atmosphere, suitable to simulate combustion waste gases

b) descaling rig with a variable speed transporting band that directs the heated blocks of steel under the jet of a plain hydraulic nozzle, and

c) cooling chamber filled with Argon.

The experiments were conducted by following (as closely as possible) the current primary hydraulic descaler conditions and design of the IJmuiden hot strip mill. A descaling nozzle of the same type as in the industrial hot mill was used, at the same system parameters:

- Everloy DNX 1243

- Speed of feeding: $0.5 \mathrm{~m} / \mathrm{s}$

- Rake angle: $15^{\circ}$

- Vertical distance nozzle-steel: $100 \mathrm{~mm}$

- System pressure: 160 bar

After descaling, the samples were rapidly cooled in Argon and photographed for a general view of the residual scale. Afterwards, all the samples were impregnated and then mounted in epoxy resin to preserve the scale, cut in cross section, polished to a 1 micron surface finish, and the surface and subsurface analysed in the optical microscope and scanning electron microscope. When required, the constitutive elements of scale and substrate were analyzed with EDX (energy dispersive X-ray spectrometry). Proportions of elements on spot EDX were determined by standardless quantification methods.

\section{Results}

\subsection{Residual Scales}

From the macroscopic images of residual scale it was not

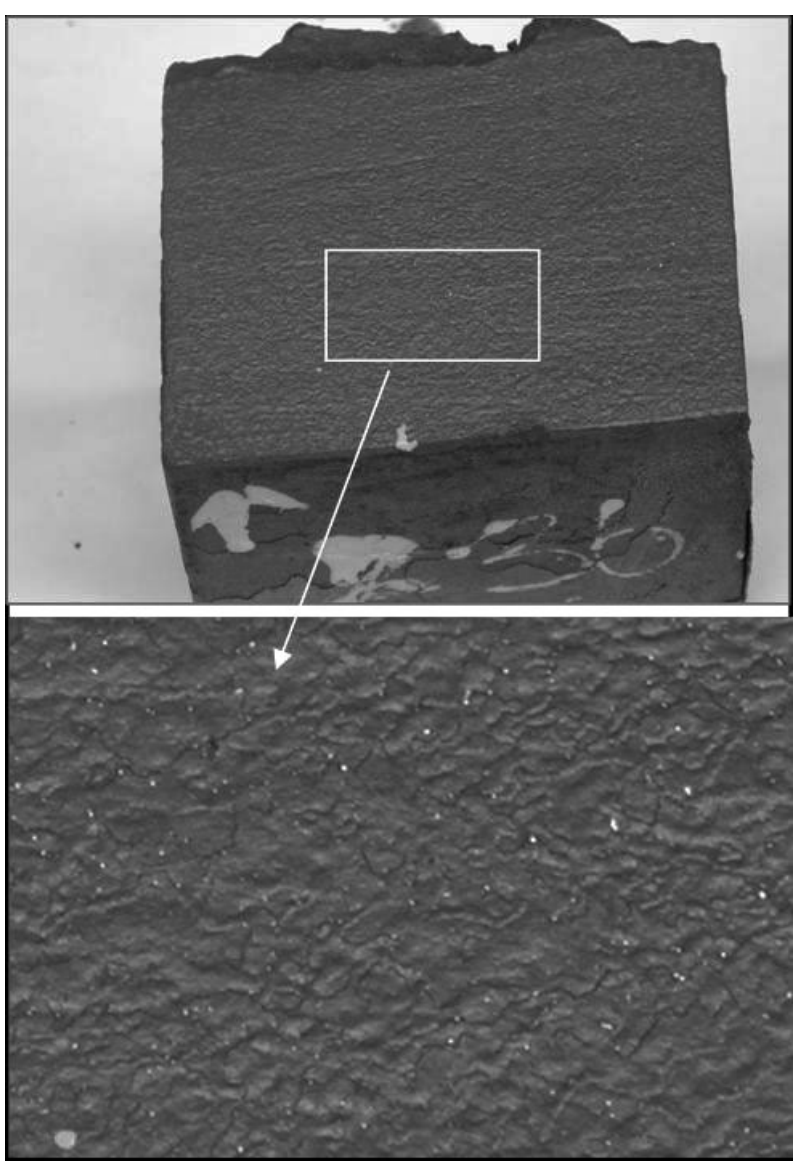

Fig. 2. Example of a block of steel after descaling. Only the top side was descaled. The right side image is a detail of the typical aspect of the surface obtained for all tests.

possible to judge the descalability of the steels processed. In most of the samples, a thin layer of loose scale was observed, which makes difficult to judge if it was primary scale formed in the furnace or secondary scale formed between descaling and cooling (see Fig. 2). For this reason, it was decided to compare the aspect of the scale in cross section, which will give a better insight on the amount and nature of the scale left in the surface and therefore entering the roughing mill.

\subsection{Scale Aspect}

To illustrate the results on scale aspect, we have selected images from samples of the three alloys with the temperature cycles that best illustrate the effects: test 1.3 (maximum final temperature) and test 4 (minimum final temperature). In Fig. 3 the images taken with optical microscopy are presented.

Figure 3 demonstrates that the residual scale can be judged by the following parameters:

1) Thickness of the residual scale. Averaged from the outermost occurrence of steel (white layer or white particles mixed with oxide) until the oxide-gas interface.

2) Level of entanglement steel-scale, which is the average thickness of the mixed oxide-steel layer; including the oxidic pegs found penetrating the grain boundaries of the steel as in alloy $\mathrm{C}$ and test 1.3 .

3) Depth of internal oxides, which are the small globu- 


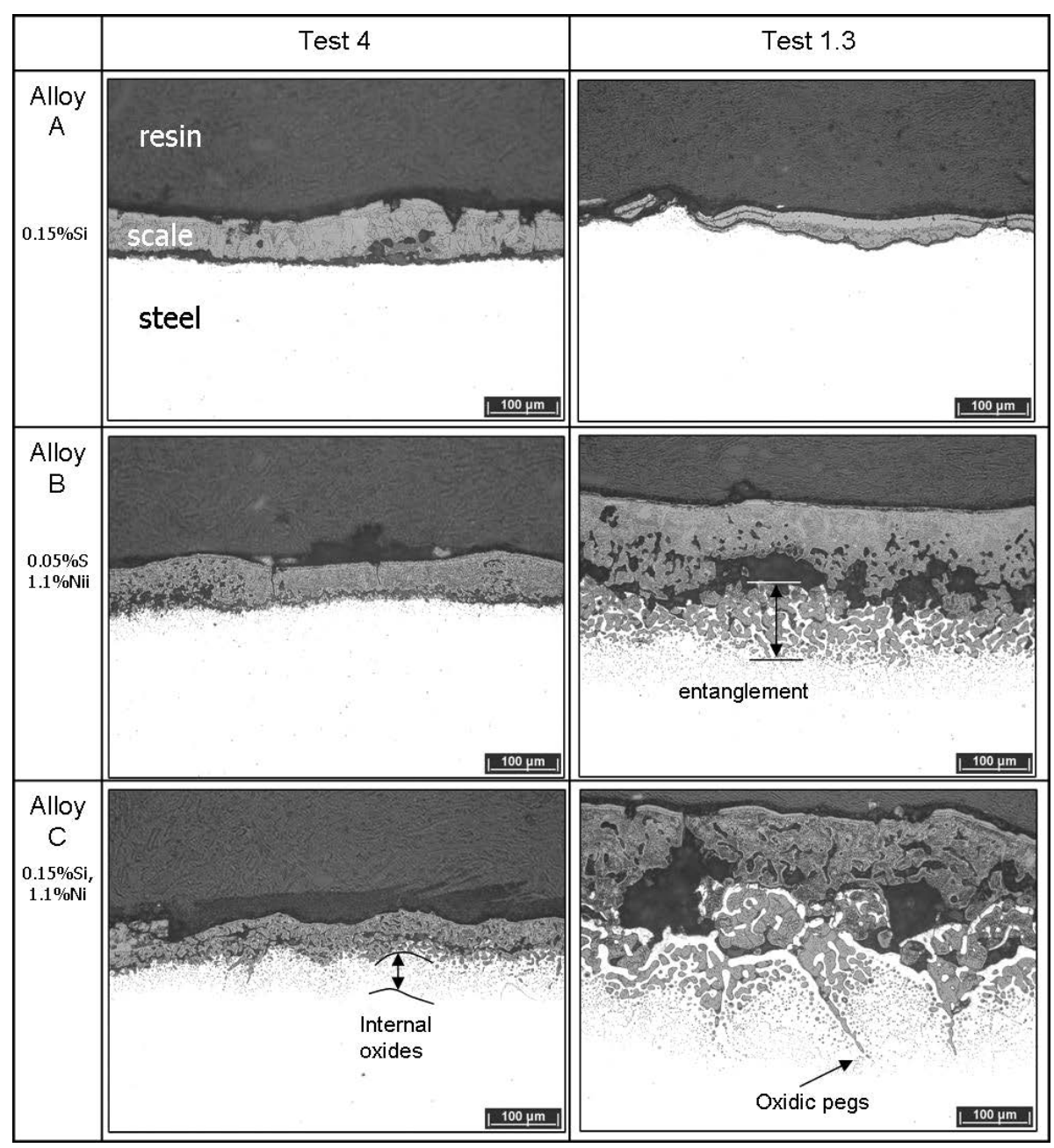

Fig. 3. Images of the scale and substrate in cross section after test 1.3 and test 4 for alloys A, B and C.

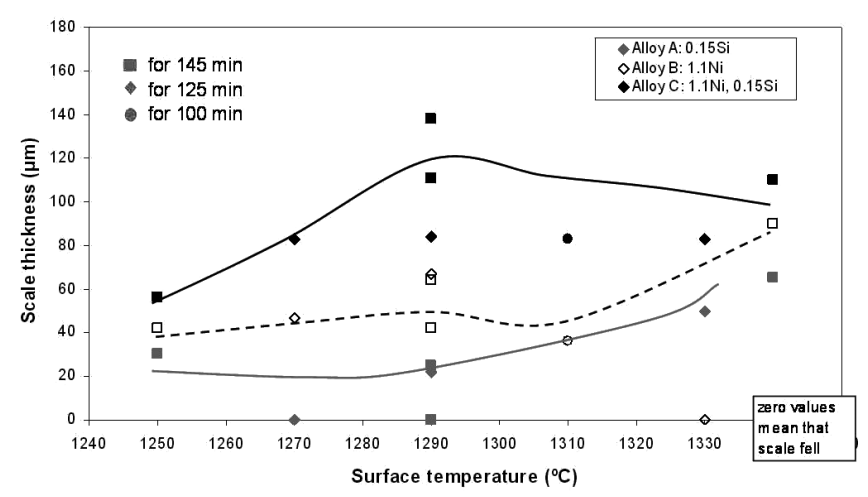

Fig. 4. Thickness of the scale left after descaling. Zero values are scales that fell during cooling, transporting or preparation and could not be measured.

lar oxide nuclei in the substrate, isolated from the oxide scale layer.

The remnant scale thickness data measured for all the samples by examining the cross section are shown in Fig. 4. The measurement is not rigorous because only a small part of the whole surface was sampled for microscopy; however it is possible to see a strong dependence on the composition and only a weak dependence on the temperature or time of reheating. The samples of Alloy $\mathrm{C}$, with both $\mathrm{Ni}$ and $\mathrm{Si}$, had residual scales of 65 to 140 microns thick; the samples of alloy $\mathrm{B}$, with only $\mathrm{Ni}$, had 36 to 90 microns oxide

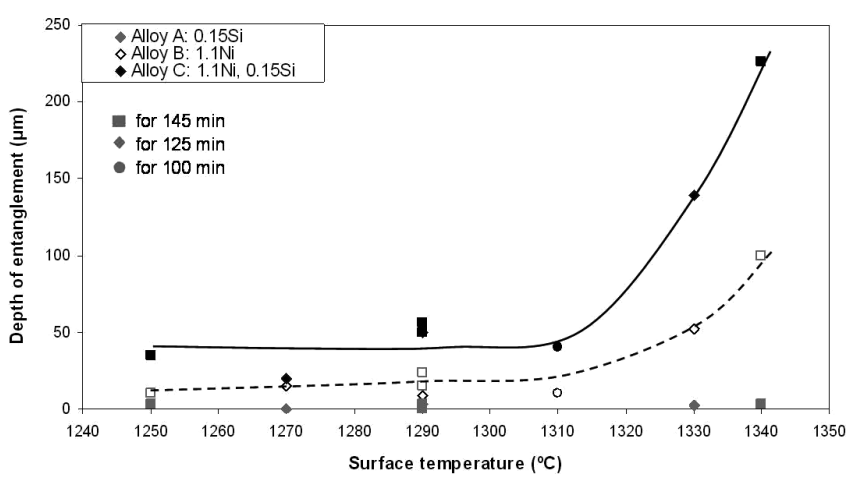

Fig. 5. Measured depth of entanglement for each of the alloys studied and each of the temperature-time cycles.

scale; while the samples of alloy A, with only $0.15 \% \mathrm{Si}$ did have scale with thickness of only 0 to 65 microns.

Figure 5 summarises the depth of entanglement observed on all samples. It is evidenced that samples of alloy A with only $0.15 \% \mathrm{Si}$ exhibited no or hardly any entanglement.

For alloy B with $1.1 \% \mathrm{Ni}$, however, significant metal/scale entanglement was observed. Figure 5 clearly shows that this entanglement is strongly dependent on the (maximum) surface temperature reached during reheating. The level of entanglement of the alloy B samples remained at modest levels of 10 to 15 microns with surface temperatures between $1210^{\circ} \mathrm{C}$ and $1310^{\circ} \mathrm{C}$, but increased steeply above 
$1310^{\circ} \mathrm{C}$, up to $100 \mu \mathrm{m}$ at $1340^{\circ} \mathrm{C}$. The reheating time (residence time in the furnace) had a less pronounced influence than the surface temperature.

For alloy $\mathrm{C}$, with $1.1 \% \mathrm{Ni}$ and $0.15 \% \mathrm{Si}$, the entanglement was on average heavier than on alloy $\mathrm{B}$. The steel-scale entanglement is strongly dependent on temperature. It can again be observed that above $1310^{\circ} \mathrm{C}$ the entanglement increases sharply, reaching even $220 \mu \mathrm{m}$ thickness at $1340^{\circ} \mathrm{C}$.

Figure 6 shows the depth of internal oxides in the substrate. The depth of internal oxides is dependent of the alloy composition, thus higher alloyed samples have deeper amount of precipitates. Moreover, there is mostly a direct dependence on surface maximum temperature, and on residence time. The sample having the same heating regime but extracted sooner from the furnace show precipitates at greater depth. However, on the sample alloy A with only silicon additions, no internal oxides are observed after reheating at high temperatures $\left(1330-1340^{\circ} \mathrm{C}\right)$, and on alloy $\mathrm{B}$, after reheating above $1290^{\circ} \mathrm{C}$ no further changes on the depth of

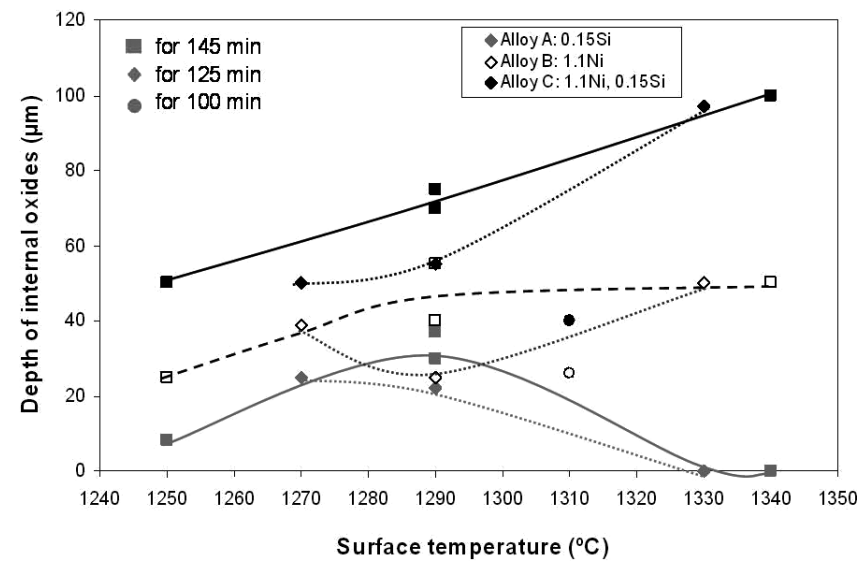

Fig. 6. Depth of internal oxides respecting the surface temperature and residence time in the furnace. intenal oxides are observed.

\subsection{Oxides Identification}

Figure 7 shows a detail of the interface steel-scale in the sample of steel $\mathrm{C}$ after test 1.3 was performed $(1.1 \% \mathrm{Ni}$ and

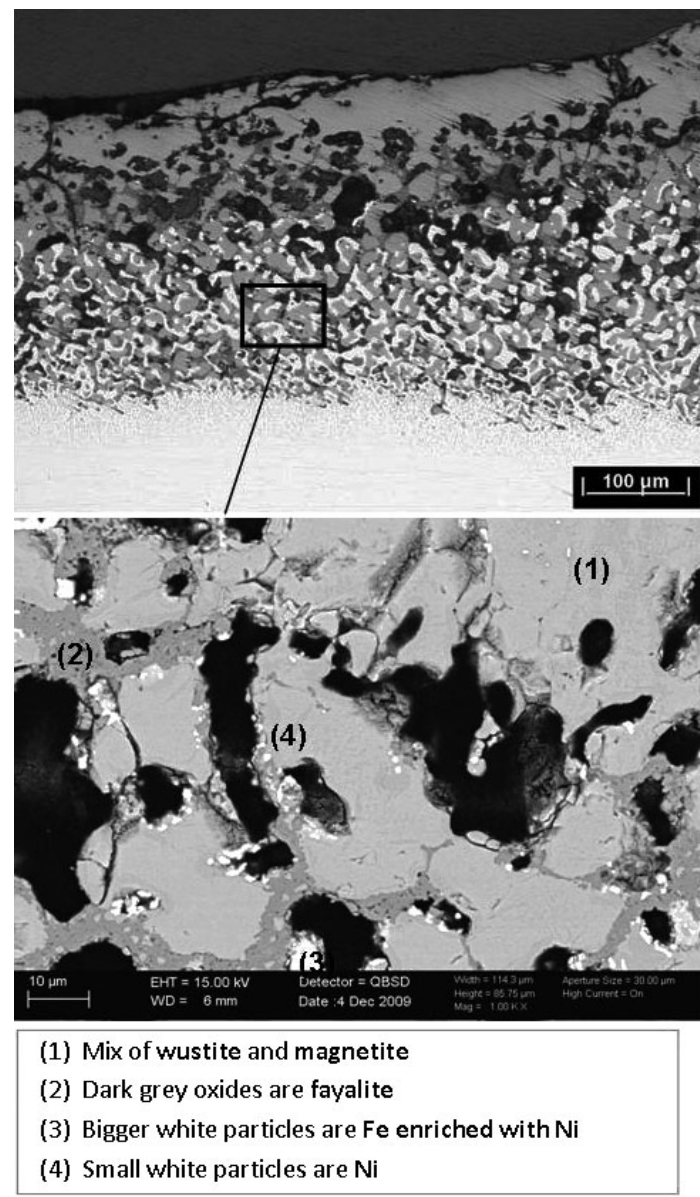

Fig. 8. Scale on steel B with only Ni $(1.1 \% \mathrm{Ni} ; 0.05 \% \mathrm{Si})$ after test 1.3. The phases were identified by spot EDX analysis.
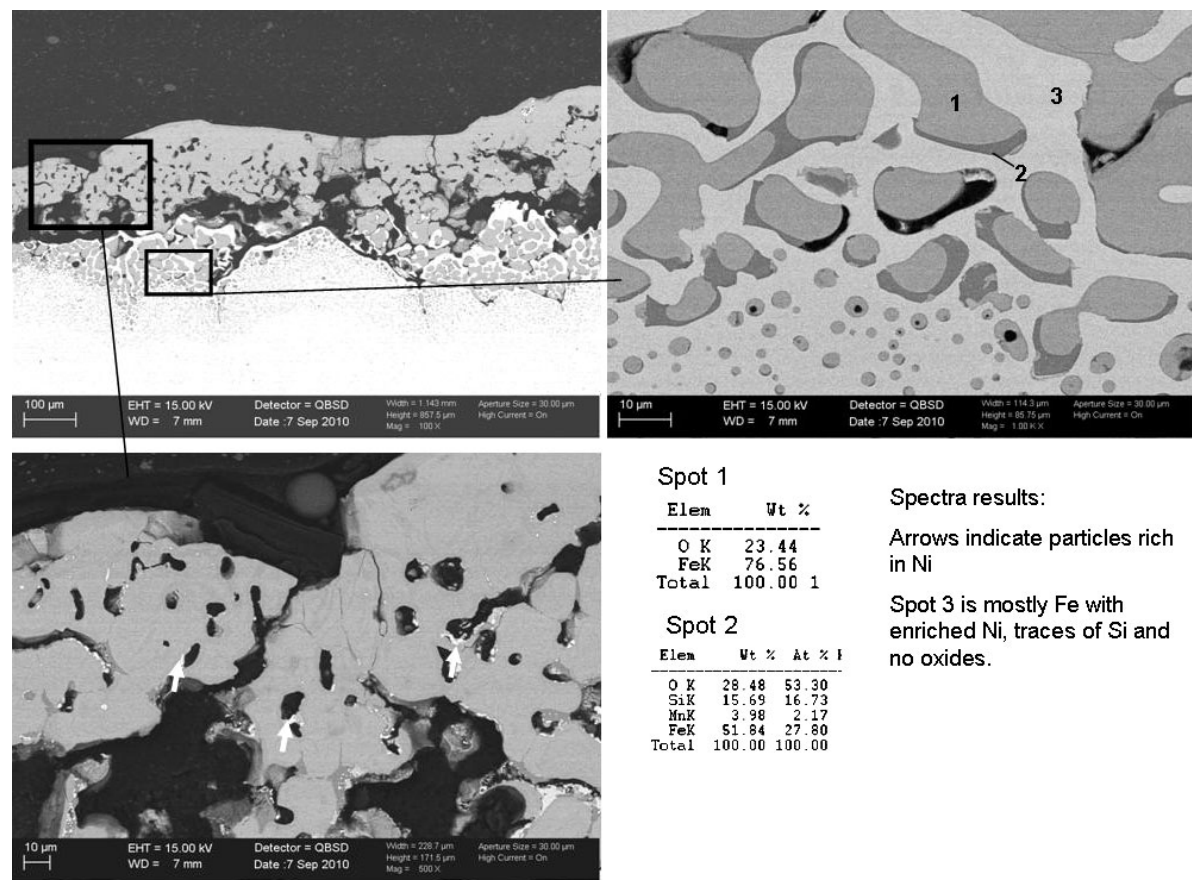

Spot 1

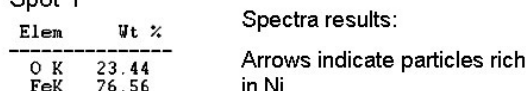

$\begin{array}{cc}\text { FeK } & 76.56 \\ \text { Total } & 100.001\end{array}$

in $\mathrm{Ni}$

Spot $2 \quad$ enriched $\mathrm{Ni}$, traces of $\mathrm{Si}$ and

Spot 3 is mostly Fe with

Elem $\mathbf{v t}_{\mathrm{t}} \%$ at $\%$ i no oxides.

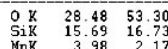

$\begin{array}{rrr}\text { MnK } & 3.98 & 2.17 \\ \text { FeK } & 51.84 & 27.80 \\ \text { tal } & 100.00 & 100.00\end{array}$

Fig. 7. Detail of the interface in sample of alloy $\mathrm{C}$ after test 1.3 . 
$0.15 \% \mathrm{Si}$ ). The internal oxides deeper into the steel were mostly manganese oxides, and towards the surface, the internal oxides consist of wüstite $\left(\mathrm{Fe}_{1-\mathrm{x}} \mathrm{O}\right)$, partially surrounded by fayalite $\left(\mathrm{Fe}_{2} \mathrm{SiO}_{4}\right)$. The quantification analysis of the darker phase of oxides identified as fayalite (spot 2) shows 15.7 wt $\% \mathrm{Si}$, which is acceptably close to the $14 \mathrm{wt} \% \mathrm{Si}$ of a perfectly stoichiometric fayalite. The quantification of the clear oxide phase identified as wüstite shows an exact stoichiometric amount of oxygen of $23 \%$. Figure 7 also shows the location of the particles of nickel, which were found only at the pores formed in the wustite/fayalite oxide. No nickel was found near the internal oxides in steel C.

For steel B, with $1.1 \% \mathrm{Ni}$ and traces of $\mathrm{Si}(0.05 \%)$, also entanglement is occurring as shown in Fig. 8. The nickelrich metallic particles are located at the walls of the pores of the oxides in the entanglement, which consist of mainly wustite and some wustite/fayalite eutectic. The presence of fayalite is remarkable, in view of the small amount of $\mathrm{Si}$ in this alloy.

\section{Discussion}

The experiments show that the formation of entangled scale-steel subsurface is highly dependent on the composition. When Ni is added to the steel, entanglement can occur, and this entanglement is enhanced if silicon is added together with $\mathrm{Ni}$. It was found that the combination $\mathrm{Si}$ and $\mathrm{Ni}$ is especially detrimental to the removability as very adherent scales reaching up to 200 microns of entangled steel-scale interface can remain after descaling. This type of interface will very likely result in red scale defect. ${ }^{4}$

The entangled scale-steel structure found in the steels with $\mathrm{Ni}$ and $\mathrm{Si}$ was formed by oxides of wustite, surrounded by fayalite (or fayalite-wustite eutectic) in a matrix of the steel. The same combination of oxides was also observed in the oxidic pegs along the grain boundaries of the steel. In the samples of the steel with only Ni and a very low Si content, the entangled structure was formed by wustite and some fayalite. Nickel-rich metallic particles were found around the pores formed in the wustite oxide scale, mostly near fayalite. These Ni particles are former Ni-rich grains that got completely engulfed by the advancing oxidation front. The remaining metallic atoms in these particles have subsequently been oxidised leaving almost pure Ni particles. Bigger particles and Ni-rich grains that are only partially engulfed still contain considerable portions of metallic $\mathrm{Fe}$ besides Ni.

The temperature of reheating plays also a role in the formation of entanglement and oxidic pegs penetrating the steel. In our tests, when the surface temperature rises above $1310^{\circ} \mathrm{C}$, both the alloys with $1.1 \% \mathrm{Ni}$ and with $1.1 \% \mathrm{Ni}+$ $0.15 \% \mathrm{Si}$ produce deeper entangled scale-steel interface. It was also found that the time of residence in the furnace (at least on the time scale used on these experiments of 100 , 125 and $145 \mathrm{~min}$ above $1000^{\circ} \mathrm{C}$ ) has little influence on the scale entangling with the steel. This inflexion point at $1310^{\circ} \mathrm{C}$ in where the entanglement depth (including oxidic pegs) sharply increases is well above the melting point of the eutectic fayalite-wustite $\left(1177^{\circ} \mathrm{C}\right)$. As our experiments were not conducted on isothermal conditions but rather fol- lowing real reheating curves for steels slab surfaces, this inflexion point seems to be an effect of both thermodynamics and kinetics. We can assert that the entanglement is enhanced by the presence of liquid oxides, the penetration into grain boundaries observed for the steel with $\mathrm{Ni}$ and $\mathrm{Si}$ is clearly liquid penetration. The amount of liquid formed and therefore the extent of entanglement must depend on the time above the melting temperature. Furthermore, according to the phase diagram $\mathrm{FeO}-\mathrm{SiO}_{2}$ higher temperature promotes the formation of liquid oxides because the proportion of $\mathrm{SiO}_{2}$ required to form liquid is increased from $\sim 23 \%$ at $1177^{\circ} \mathrm{C}$ to a range from $\sim 10$ to $40 \mathrm{wt} \%$ at $1310^{\circ} \mathrm{C}$. The exact occurrence of this inflexion point can be further studied, but for our purposes, it has been demonstrated that the optimum industrial reheating process window involves a gentle process avoiding slab-surface temperatures above $1310^{\circ} \mathrm{C}$.

The formation of entanglement is not only enhanced by the liquid oxide presence, it was clearly observed that the synergetic effect of $\mathrm{Ni}$ and $\mathrm{Si}$ enhances greatly the entanglement depth. The mechanism proposed by Fukagawa et al. ${ }^{4)}$ suggested that Ni gets enriched at the interface scale-steel, retarding external oxidation, thus promoting internal oxidation. Furthermore, they suggest that Ni remains surrounding these internal oxides. We have not found evidence of $\mathrm{Ni}$ around or near the internal oxides, but rather at the walls of pores formed in the iron oxide, and mostly near fayalite. It is also unlikely that the nickel moves towards the surface, because the oxygen activity remains constant at the interface wustite-steel and it is too low to oxidize Ni. Thus, there is no driving force to promote transport of Ni towards the surface. In contrast, since Fe has a higher oxygen affinity than $\mathrm{Ni}$, there is a net driving force for enriched $\mathrm{Ni}$ to diffuse away from the surface, into the bulk of the steel. However, the diffusivity of $\mathrm{Ni}$ is obviously too low to prevent $\mathrm{Ni}$ enrichment and entanglement by the growing oxides. Our proposal to explain the mechanism of entanglement formation for steels with only $\mathrm{Si}$, only $\mathrm{Ni}$ and the synergetic effect of both $\mathrm{Ni}$ and $\mathrm{Si}$ is explained in the diagrams of Fig. 9 including the effect of liquid oxide formation.

The depth of internal oxides and the thickness of the remnant scale were also strongly related to composition and temperature. The internal oxides are clearly enhanced by the presence of $\mathrm{Ni}$ or both $\mathrm{Ni}$ and $\mathrm{Si}$ in the alloy. Internal oxides are formed when oxygen can penetrate the steel and that only occurs when the molar fraction of the oxidised element is below a critical value dependent on the diffusivities of the oxygen and the element oxidising. ${ }^{8)}$ In a slab reheating furnace, the oxygen potential is enough to oxidise all elements in the alloy (except nickel). The oxygen potential at the interface is determined by the local $\mathrm{Fe} / \mathrm{FeO}$ equilibrium. Ahead of the interface, oxygen atoms are diffusing into the subsurface. The $\mathrm{pO}_{2}$ is decaying with increasing depth but due to the higher oxygen affinity of $\mathrm{Mn}$ and $\mathrm{Si}$ (as compared to $\mathrm{Fe}$ ), internal precipitation of $\mathrm{MnO}$ and $\mathrm{SiO}_{2}$ will occur up to a certain depth (i.e. the depth at which $\mathrm{pO}_{2}$ is just high enough for the $\mathrm{Mn} / \mathrm{MnO} ; \mathrm{Mn} / \mathrm{MnSiO}_{\mathrm{x}}$; or $\mathrm{Si} / \mathrm{SiO}_{2}$ equilibri$\mathrm{um})$. The $\mathrm{FeO}$ in the external scale as well as in the oxidic pegs acts as continuous source of oxygen diffusing into the subsurface of the metal, causing growth of the internal oxidation zone. In parallel, the oxidation front continues grow- 


\begin{tabular}{|c|c|c|}
\hline With only Si & With only Ni & With Ni and Si \\
\hline \multicolumn{3}{|l|}{ Oxidation at $\mathrm{T}<1177^{\circ} \mathrm{C}$} \\
\hline$\bullet \bullet \bullet \bullet \bullet$ & 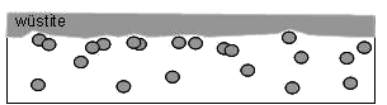 & {$\left[\begin{array}{cccccc}0 & 0,000 & 0.000 & 0 & 0 & 0 \\
0 & 0 & 0 & 0 & 0 & 0 \\
0 & 0 & 0 & 0\end{array}\right]$} \\
\hline $\begin{array}{l}\text { - } \mathrm{FeO} / \mathrm{Fe}_{2} \mathrm{SiO}_{4} \text { nuclei form internally and } \\
\text { externally, wustite forms at depleted } \mathrm{Si} \\
\text { positions. }\end{array}$ & $\begin{array}{l}\text { Nickel sits in metallic form } \\
\text { Ni enrichment: pushed forward by } \\
\text { moving oxidation front }\end{array}$ & $\begin{array}{l}\text { - } \mathrm{FeO} / \mathrm{Fe}_{2} \mathrm{SiO}_{4} \text { nuclei form internally and } \\
\text { externally, wustite forms at depleted } \mathrm{Si} \\
\text { positions } \\
\text { Nickel enrichment: pushed forward by } \\
\text { moving oxidation front }\end{array}$ \\
\hline \multicolumn{3}{|l|}{ Oxidation at $\mathrm{T}>1177^{\circ} \mathrm{C}$} \\
\hline magnerte & $\begin{array}{l}\text { hematite } \\
\begin{array}{lllllll}\text { magnettie } & & & & & & \\
\infty & 0 & 0 & 0 & 8 & \infty & 0 \\
0 & 0 & 0 & 0 & 0 & 0 \\
0 & 0 & & & 0 & 0 \\
\end{array}\end{array}$ & \\
\hline $\begin{array}{l}\mathrm{FeO} / \mathrm{Fe}_{2} \mathrm{SiO}_{4} \text { is liquid: } \\
\text { - Forms islands on the interface with } \\
\text { wustite } \\
\text { - } \mathrm{Can} \text { penetrate the grain boundaries of } \\
\text { the wustite and the steel forming } \\
\text { oxidic pegs } \\
\text { - Accelerates } \mathrm{Fe} \text { diffusion thus the total } \\
\text { oxide layer is thicker than at lower T } \\
\text { - The entanglement extent depends on } \\
\text { the Si content }\end{array}$ & $\begin{array}{l}\text { Oxidation is irregular due to obstruction } \\
\text { by Ni-rich particles } \\
\text { Ni particles engulfed by the solid oxide } \\
\text { front } \\
\mathrm{Ni} \text { retards Fe diffusion, thinner oxides } \\
\text { will form } \\
\text { Hematite will also form }\end{array}$ & 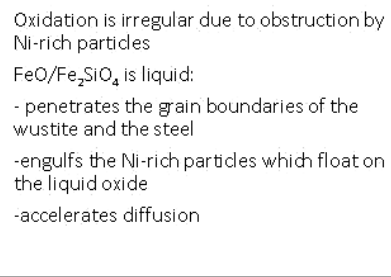 \\
\hline \multicolumn{3}{|c|}{ Cooling down to room temperature } \\
\hline $\mathrm{FeO} / \mathrm{Fe}_{2} \mathrm{SiO}_{4}$ solidifies and shrinks, & & \\
\hline $\begin{array}{l}\mathrm{FeO} / \mathrm{Fe}_{2} \mathrm{SiO}_{4} \text { solidifies and shrinks, } \\
\text { forming pores }\end{array}$ & $\begin{array}{l}\text { An entangled layer of wustite and steel } \\
\text { is formed. Ni sits in the wustite pores }\end{array}$ & $\begin{array}{l}\mathrm{FeO} / \mathrm{Fe}_{2} \mathrm{SiO}_{4} \text { solidifies and shrinks, forming } \\
\text { pores }\end{array}$ \\
\hline
\end{tabular}

Fig. 9. Proposed mechanism of occurrence of entanglement due to nickel and silicon.

ing depending on the diffusivity (which is greatly enhanced by the presence of liquid oxides) and the internal oxides get consumed.

The mechanisms illustrated in Fig. 9 and our analysis on internal oxidation explains the observations made in this report:

- For steel without $\mathrm{Ni}$ and $0.15 \% \mathrm{Si}$, the oxides form internally in nodules and externally in approximate homogeneous layers. Fayalite-wustite eutectic only forms when enough $\mathrm{Si}$ can accumulate at metal/steel interface (locally a concentration of $14 \mathrm{wt} \%$ of $\mathrm{Si}$ is required), thus it is likely that only small pockets of liquid were forming when heated above $1177^{\circ} \mathrm{C}$ causing very little penetration of liquid phases into grain boundaries. The oxidation front growth is faster than the internal oxidation and it consumes the internal oxides. The resulting interface is uniform even at the highest temperatures.

- For steel with $1.1 \% \mathrm{Ni}$ and $0.05 \% \mathrm{Si}$, the oxidation front is initially uniform, but $\mathrm{Ni}$ being nobler than $\mathrm{Fe}$ is not oxidised, and it is pushed forward by the moving oxidation front. Therefore, Ni gets enriched in the metallic phase at the metal/scale interface. Under reheating conditions, the diffusivity of $\mathrm{Ni}$ is too low to eliminate this $\mathrm{Ni}$ enrichment by diffusion of $\mathrm{Ni}$ into the bulk of the steel. Ni-rich metallic grains are obstructing the further movement of the oxidation front, which becomes nonuniform. When the oxide solidifies, it is forming a layer of entangled structure with the steel. The oxidation front consumes the internal oxides but its growth is precluded by the presence of $\mathrm{Ni}$ that is affecting $\mathrm{Fe}$ diffusivities, thus the internal oxide formation and the front growth are in competition. The resulting interface is an irregular layer of entanglement with some internal oxides

- For steel with $1.1 \% \mathrm{Ni}$ and $0.15 \% \mathrm{Si}$, the phenomena described above are repeated, but the amount of $\mathrm{Si}$ is higher and hence more $\mathrm{FeO} / \mathrm{Fe}_{2} \mathrm{SiO}_{4}$ which is in liquid phase above $1177^{\circ} \mathrm{C}$. At the locations where the external oxidation front has advanced deepest into the steel (i.e. the tips of the entanglement nets due to the Ni presence explained above), pools of liquid concentrate. These liquid oxides will penetrate grain boundaries of steel and form oxidic pegs. This liquid increases the diffusion of $\mathrm{Si}$ and $\mathrm{Fe}$ and accelerates oxide formation causing more formation of wustite/fayalite phases which continues being liquid and growing in irregular fashion plus penetrating grain boundaries. The higher the temperature above the melting point of fayalite, the lower the concentration of $\mathrm{SiO}_{2}$ required forming more liquid, thus again enhancing the presence of liquid. The oxidation front is very irregular and internal oxidation forms around the oxidic pegs, giving the perception that internal oxidation is deeper. The resulting interface is a synergetic effect of the entanglement caused by the presence of $\mathrm{Ni}$ and the oxidic pegs caused by the liquid oxides. 


\section{Conclusions}

- The oxidation experiments show that synergistic effects occur during the oxidation of alloys containing $\mathrm{Ni}$ and Si. This effect consists of increasing the adherence of oxide scale to the steel substrate by forming an entangled layer with oxidic pegs.

- In order to maximize descalability of $(\mathrm{Ni}, \mathrm{Si})$-alloyed steels slabs, the metal/scale entanglement has to be minimised. In this respect, the slab surface temperature is the most important parameter. A gentle, smooth reheating process is required in which slab surface temperatures exceeding $1300^{\circ} \mathrm{C}$ should be avoided.

- Alloys containing nickel alone require less stringent conditions of processing. However, very small amounts of $\mathrm{Si}(0.05 \mathrm{wt} \%)$ are already forming liquid phases that can be increasing the adhesion of scale to the steel substrate.

- The analysis and quantification of the interface formed between oxide scale and steel can be a method to interpret the descalability of certain steel without the need of more complicated descaling studies.

\section{REFERENCES}

1) H. F. Marston, R. Ratcliffe, M. Steer, M. Bugdol, J. R. Gonzales, J. M. Llanos, J. Niska, B. Sjogren, M. Kuhlmann, F. Widmann, R. Klima, G. Leprince and M. Picard: Tailoring Scale Characteristics during Steel Processing, EUR: 21427-R602, European Research Commission, Luxembourg, (2004).

2) B. Stewart, H. F. Marston, N. Zacchetti, S. Bellini, R. Orosz, J. Niska and D. C. Martin: Control of Scale during Steel Processing, EUR 24261, European Research Commission, Luxembourg, (2010).

3) T. Asai, T. Soshiroda and M. Miyahara: ISIJ Int., 37 (1997), 272.

4) T. Fukagawa, H. Okada and Y. Maehara: ISIJ Int., 34 (1994), 906.

5) T. Fukagawa: Tetsu-to-Hagané, 82 (1996), 63.

6) Verein Deutscher Eisenhuttenleute: Slag Atlas, Verein Deutscher Eisenhuttenleute, Germany, (1995), 255.

7) H. Okada, T. Fukugawa, H. Ishihara, A. Okamoto, M. Azuma and Y. Matsuda: ISIJ Int., 35 (1995), 886.

8) C. Wagner: Z. Elektrochemie, 63 (1959), 772. 